\title{
Características histopatológicas e imunohistoquímicas das lesões cutâneas e da mucosa oral na histoplasmose disseminada de portadores da síndrome da imunodeficiência adquirida (AIDS)
}

\author{
Histopathology and immunohistochemistry of skin and oral \\ mucosa in disseminated histoplasmosis associated with \\ acquired immunodeficiency syndrome (AIDS) \\ Solange Corrêa Garcia Pires D'Avila e Edmundo Chapadeiro
}

\begin{abstract}
Resumo A análise histopatológica e imunohistoquímica de 25 biópsias cutâneas e da mucosa oral de portadores da associação AIDS e histoplasmose mostrou o seguinte: 1) em 18 casos as lesões cutâneas eram múltiplas e se apresentavam sob a forma de pápulas (eritematosas, violáceas ou acastanhadas), úlceras, vesículo-pústulas e eram distribuídas por todo tegumento cutâneo; Em sete casos as lesões se localizavam na mucosa da língua, palato, úvula e eram do tipo ulcerado ou moruliforme; 2) histologicamente as lesões apresentavam quatro aspectos distintos: macrofágico difuso; granulomatoso; vasculítico com leucocitoclasia; e com escassa reação inflamatória; 3) a tipagem dos linfócitos $T$ e $B$ e dos macrófagos através dos anticorpos monoclonais mostrou que a resposta imunológica ao Histoplasma capsulatum é predominantemente do tipo celular nos quatro tipos histológicos; 4) o teste imunohistoquímico para o fungo nas lesões confirmou o diagnóstico morfológico de $\mathrm{H}$. capsulatum.
\end{abstract}

Palavras-chaves: Pele. Mucosa oral. Histoplasmose. Histoplasmose disseminada. AIDS.

\begin{abstract}
Biopsy specimens of the skin and oral mucosa from twenty-five patients bearing the disseminated form of histoplasmosis ( $\mathrm{H}$. capsulatum) associated with AIDS (aquired immunodeficiency syndrome) were studied by histologic and immunohistochemistry techniques. Histologically, the skin lesions showed four different patterns: diffuse macrophage, granulomatous, vasculitic with leucocytoclastic and scarce inflammatory reaction. The cell markers for macrophages, lymphocytes $B$ and $T$ and $\mathrm{H}$. capsulatum revealed CD68, UCHL-1 and L26 associated with variable amounts of fungi.
\end{abstract}

Key-words: Skin. Oral mucosa. Histoplasmosis. Disseminated histoplasmosis. AIDS.

Curso de Pós-graduação em Patologia Humana da Faculdade de Medicina do Triângulo Mineiro, Uberaba, MG

Endereço para correspondência: Dra. Solange C.G.P. D'Ávila. Rua Siqueira Campos 1590, Bairro Boa Vista, 15010-210 São José do Rio Preto, SP.

Recebido para publicação em 01/10/97. 
Em décadas recentes, o emprego de terapêuticas antineoplásicas imunossupressoras e o surgimento da AIDS têm contribuído para o aumento da incidência da histoplasmose disseminada. Esta última, aparece como importante doença oportunística2681516171819. Nos Estados Únidos, a prevalência desta associação varia de 2,7 a 50\%, para as áreas não endêmicas e endêmicas, respectivamente 15. Em nosso meio, desconhecemos levantamentos epidemiológicos da associação AIDS/ histoplasmose, particularmente no que se refere às lesões cutâneas e da mucosa oral, como as que ocorrem em outros países.

Parece-nos, portanto, justificável o relato, não só dessa associação, mas também as características clínicas, histopatológicas e imunohistoquímicas dessas das cutâneas e da mucosa oral em uma região do país, onde a referida micose constitui endemia freqüente.

\section{MATERIAL E MÉTODOS}

Material. Consta de 25 biópsias obtidas por punch, sendo 18 de lesões da pele e 7 de lesões da mucosa oral com diagnóstico de AIDS e nas quais firmamos o diagnóstico de histoplasmose baseado no encontro de células fúngicas com características morfológicas de Histoplasma capsulatum. As mesmas eram procedentes do ambulatório de Dermatologia ou do setor de Moléstias Infecciosas do Hospital de Base da Faculdade Estadual de Medicina de São José do Rio Preto, SP e foram processadas no Laboratório de Patologia desse Hospital. Dezenove indivíduos eram do sexo masculino e seis do sexo feminino; vinte deles eram brancos e cinco pretos; as idades variaram entre 21 e 46 anos.

Os diagnósticos de AIDS foram baseados nos critérios do Center for Disease Control of Atlanta 4 .

Métodos. As biópsias foram fixadas em solução aquosa de formalina a $10 \%$, desidratadas em concentrações crescentes de álcool etílico, diafanizadas em xilol, incluídas em parafina e submetidas a cortes histológicos de 5 micrômetros. A seguir foram coradas pelos métodos de hematoxilina-eosina e mucicarmim. O mucicarmim foi utilizado para o diagnóstico diferencial com o Criptococcus neoformans. Realizou-se também a impregnação pela prata segundo o método de Grocott-prata- metanamina para caracterização do fungo. Doze biópsias foram também submetidas a estudo imunohistoquímico, para pesquisa e caracterização do Histoplasma capsulatum e para marcação de linfócitos T, B e macrófagos. Para tal utilizou-se a reação estreptavidina-biotina conforme descrição a seguir.

\section{1 ${ }^{\text {a }}$ etapa:}

a) cortes de 4 micrômetros foram montados em lâminas tratadas com silene;

b) submetidos à desparafinação em xilol por 20 minutos em estufa a 60 graus, e passados no xilol por 10 minutos em temperatura ambiente;

c) hidratados em concentrações decrescentes de álcool (3 álcoois absolutos, 1 álcool 95, 1 álcool 70), água corrente por 5 minutos e água destilada.

\section{2a etapa:}

Bloqueio da peroxidase endógena:

a) os cortes foram tratados por 2 vezes em solução 1:1 de água oxigenada a 20 volumes e metanol por 10 minutos no escuro;

b) lavados em água corrente e passados em água destilada;

c) passados em solução tamponada com fosfato (PBS) ph 7,4.

\section{3a etapa:}

Anticorpo primário: os cortes foram tratados com solução de 1:1000 de anticorpo policlonal anti-histoplasma e soro-albumina-bovina (BSA) e deixados na geladeira por 18 horas a $4^{\circ} \mathrm{C}$.

\section{4a etapa:}

Anticorpo secundário:

a) os cortes foram lavados com PBS por 10 minutos;

b) tratados com anticorpo secundário (cabracoelho) biotinilado, diluição de $1: 1000$, a $37^{\circ} \mathrm{C}$ por 30 minutos;

c) deixados em PBS por 10 minutos.

\section{5a etapa:}

Anticorpo terciário:

a) os cortes foram tratados com anticorpo terciário Streptavidin-Biotin-Complex (SABC) diluição de $1: 1000$ por 30 minutos a $37^{\circ} \mathrm{C}$;

b) deixados em PBS por 10 minutos.

\section{6a etapa:}

Revelação-cromógeno:

a) preparou-se solução contendo $30 \mathrm{mg}$ de Diamino-benzidina diluída em $100 \mathrm{ml}$ de PBS;

b) a mesma foi filtrada e misturada com 600 microlitros de água oxigenada a 20 volumes; 
c) os cortes foram colocados nesta solução por I,5 a 2 minutos. lavados em água corrente, contracorados com hematoxilina, novamente lavados com água corrente, desidratados em concentrações crescentes de álcool, diafanizados no xilol e montados em permalt.

Resultados: fundo corada em azul e o antígeno (histoplasma) em castanho.

Os exoantígenos e o anti-soro foram produzidos no Laboratório de Micologia Médica do Instituto de Medicina Tropical de São Paulo. Como referência foram utilizados anti-soro e antígeno $\mathrm{H}$ e M de Histoplasma capsulatum, fornecidos pelo Center for Disease Control (CDC/Atlanta, USA, lote 78-0326) ${ }^{9}$.

A padronização da reação foi realizada no Laboratório de Patologia de Moléstias Infecciosas da FMUSP pelas biólogas Carla Pagliorie e Débora C. Aziz Rocha sob a supervisão da Profa. Maria Irmã Seixas Duarte (Tabela 1).

Para pesquisa e caracterização imunohistoquímica dos linfócitos T, B e macrófagos realizou-se a reação estreptavidinabiotina utilizando-se os seguintes reagentes:

Tabela 1 - Padronização de anti-soros.

\begin{tabular}{|c|c|c|c|c|}
\hline Órgão/Fungo & Ac. anti-Candida $s p$ & Ac. anti- $P$. carinii & Ac. anti-H. caspulatum & Ac. anti-P-b113 \\
\hline 1. gânglio/H. capsulatum+ & negativo & negativo & +++ & + \\
\hline 2. fígado/H. caspulatum + & negativo & negativo & +++ & negativo \\
\hline 3. pulmão/H. caspulatum + & negativo & negativo & +++ & + \\
\hline 4. pulmão/H. caspulatum + & negativo & negativo & +++ & negativo \\
\hline 5. pulmão/H. caspulatum + & negativo & negativo & +++ & negativo \\
\hline 6. $\mathrm{rim} /$ Candida $s p+$ & +++ & negativo & negativo & + \\
\hline 7. rim/Candida sp+ & +++ & negativo & negativo & + \\
\hline 8. pulmão/Candida sp+ & +++ & negativo & negativo & negativo \\
\hline 9. cavidade oral/Candida $s p+$ & +++ & negativo & negativo & negativo \\
\hline 10. pulmão/Pneumocytis carinii + & negativo & +++ & negativo & negativo \\
\hline 11. pulmão/Pneumocytis carinii + & negativo & +++ & negativo & negativo \\
\hline 12. pulmão/Pneumocytis carinii + & negativo & +++ & negativo & negativo \\
\hline 13. pele/Esporotrico + & + & negativo & negativo & negativo \\
\hline 14. sistema nervoso/C. neoformans + & negativo & negativo & negativo & negativo \\
\hline 15. pulmão/P. brasiliensis+ & + & negativo & negativo & +++ \\
\hline
\end{tabular}

Laboratório de patologia de moléstias infecciosas da FMUSP: Prof ${ }^{a}$. Maria Irmã Seixas Duarte; Carla Pagliori; Débora Cristina Aziz Rocha.

Anticorpos primários:

L26 (B-cells, CD20), monoclonal: mouse/ supernatant, Code-MU238-UC, Biogenex, clone L26, diluição 1:200.

. UCHL-1 (CD45 RO, T-cell), monoclonal: mouse /supernatant. Code-MU113-VC, Biogenex, clone UCHL-1, diluição 1:100

CD68 (anti-Human macrophage,CD68). Clone KP1. Code-M0814, Lot 105, DAKO, diluição $1: 5000$
Revelador cromógeno: 3 amino 9 ethil carbazole Code- 5-5754, Sigma.

Para quantificação destas células utilizou-se a seguinte escala:

0 ausência de células nos cortes examinados

+ escassas células

++ pequena quantidade de células

+++ moderada quantidade de células

++++ grande quantidade de células

\section{RESULTADOS}

Em dez dos 25 pacientes, as lesões cutâneas eram múltiplas e localizavam-se preferentemente na face, tronco e membros superiores, sob forma de pápulas eritematosas violáceas ou acastanhadas, com diâmetro entre 0,5 e $1,5 \mathrm{~cm}$; em sete casos, as lesões cutâneas mostravam-se ulceradas, medindo entre 0,5 a $3,0 \mathrm{~cm}$ nos seus diâmetros maiores; em um caso a lesão era vesículo-pustulosa (Figuras 1, 2, 3 e 4).

Em sete casos, as lesões ocorreram na mucosa e localizavam-se na língua $(n=4)$, palato $(n=2)$ e úvula $(n=1)$. Todas as lesões eram ulceradas, exceto em um caso no qual se apresentavam sob forma de estomatite moruliforme. 


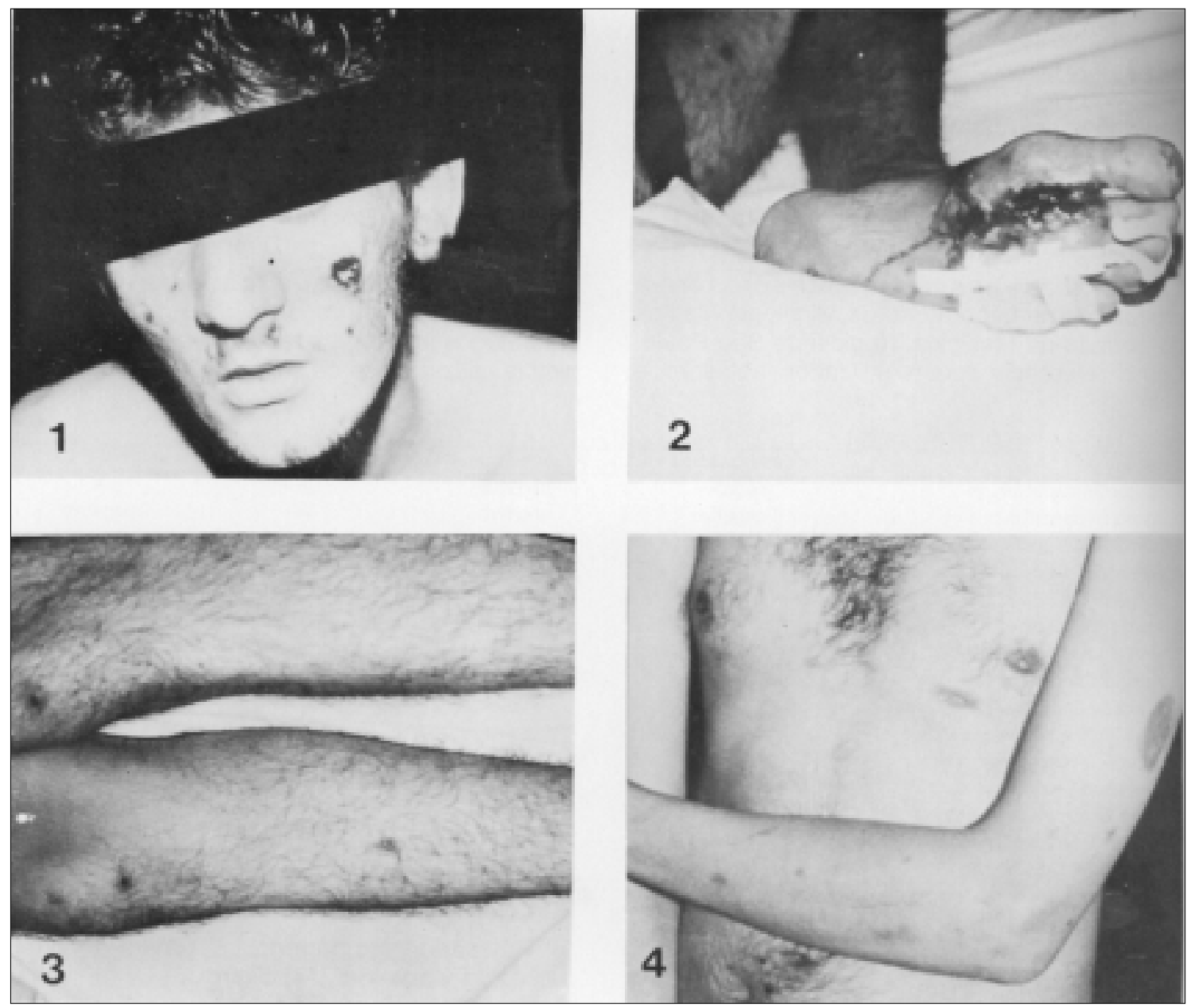

Figura 1- Lesões ulceradas na face, com diâmetros variando entre 0,5 e 1,5cm, apresentam bordas elevadas e fundo hemorrágico.

Figura 2 - Lesão ulcerada em região plantar medindo 3,0cm de extensão com bordas irregulares e fundo hemorrágico. Figura 3 - Pústulas eritemato-violáceas com 0,5 a 1,0cm em membros inferiores.

Figura 4 - Pápulas eritematosas com diâmetros variando entre 0,5 e 2,5cm distribuídas no tronco e membros superiores.

A Tabela 2 resume as características clínicas e histopatológicas (descritas a seguir) das lesões dos vinte e cinco pacientes.

Histologicamente as lesões cutâneas apresentaram quatro tipos de reação tecidual: a) macrofágico difuso: foi observado em 15 casos e caracterizou-se por apresentar na derme infiltrado inflamatório difuso, de células mononucleares com grande quantidade de células CD68 (macrófagos), pequena quantidade de células UCHL-1 (linfócitos T) e ausência ou escassas células L26 (linfócitos B). Em todos os casos, observou-se grande quantidade de células fúngicas, predominantemente no interior dos macrófagos (Figuras 5, 9, 10, 11, 12, 13) coradas com as técnicas rotineiras e pela imunohistoquímica. Um dos casos deste padrão apresentou associação com sarcoma de Kaposi, o qual além do infiltrado macrofágico difuso, mostrava proliferação irregular de células endoteliais atípicas, focos de necrose e extravasamento de hemáceas; b) vasculítico 
Tabela 2 - Dados clínicos e tipos histológicos das lesões cutâneas e da mucosa oral, em 25 aidéticos portadores de histoplasmose disseminada.

\begin{tabular}{|c|c|c|c|}
\hline Casos & Idade/Sexo/Cor & Aspecto clínico & Tipo histológico \\
\hline 1 & $31 / \mathrm{F} / \mathrm{br}$ & Pápulas eritematosas de até $1,5 \mathrm{~cm}$ difusas em todo o tegumento cutâneo & macrofágico difuso \\
\hline 2 & $25 / \mathrm{M} / \mathrm{br}$ & Lesão ulcerada da úvula com $1 \mathrm{~cm}$ & macrofágico difuso \\
\hline 3 & $27 / \mathrm{M} / \mathrm{br}$ & Pápulas eritemato-violáceas da face e tronco com $0,5 \mathrm{~cm}$ & macrofágico difuso \\
\hline 4 & $28 / \mathrm{M} / \mathrm{br}$ & $\begin{array}{l}\text { Difuso em todo o tegumento cutâneo; máculas e úlceras com } \\
\text { diâmetros variáveis }\end{array}$ & $\begin{array}{l}\text { vasculítico com } \\
\text { leucocitoclasia }\end{array}$ \\
\hline 5 & $38 / \mathrm{M} / \mathrm{br}$ & Difusa em todo o tegumento cutâneo; úlceras com 0,5 a $2 \mathrm{~cm}$ & $\begin{array}{l}\text { vasculítico com } \\
\text { leucocitoclasia }\end{array}$ \\
\hline 6 & $48 / \mathrm{M} / \mathrm{nbr}$ & $\begin{array}{l}\text { Face, tronco e membros superiores; pápulas acastanhadas, } \\
\text { algumas verrugosas }\end{array}$ & macrofágico difuso \\
\hline 7 & $21 / \mathrm{M} / \mathrm{br}$ & Tronco; úlceras com bordas elevadas & $\begin{array}{l}\text { vasculítico com } \\
\text { leucocitoclasia }\end{array}$ \\
\hline 8 & $30 / \mathrm{M} / \mathrm{nbr}$ & Face, tronco e membros superiores; pápulas com 2 a $6 \mathrm{~mm}$ & $\begin{array}{l}\text { vasculítico com } \\
\text { leucocitoclasia }\end{array}$ \\
\hline 9 & $28 / \mathrm{F} / \mathrm{br}$ & Língua; úlcera com 1,5cm & macrofágico difuso \\
\hline 10 & $41 / \mathrm{F} / \mathrm{nbr}$ & Tronco e membros superiores; pápulas eritematosas com 0,5 a $1,5 \mathrm{~cm}$ & $\begin{array}{l}\text { escassa reação } \\
\text { inflamatória }\end{array}$ \\
\hline 11 & $26 / \mathrm{M} / \mathrm{br}$ & Difusa em todo tegumento cutâneo; pápulas eritemato-violáceas & $\begin{array}{l}\text { escassa reação } \\
\text { inflamatória }\end{array}$ \\
\hline 12 & $24 / \mathrm{M} / \mathrm{br}$ & Face, palmas e plantas; vesículo-pústulas & macrofágico difuso \\
\hline 13 & $58 / \mathrm{M} / \mathrm{br}$ & Língua; úlcera com $1 \mathrm{~cm}$ & macrofágico difuso \\
\hline 14 & $28 / \mathrm{M} / \mathrm{br}$ & Face; pápulas com $0,7 \mathrm{~cm}$ de diâmetro médio & macrofágico difuso \\
\hline 15 & $26 / \mathrm{M} / \mathrm{br}$ & Língua; úlcera com 1,5cm de diâmetro & macrofágico difuso \\
\hline 16 & $28 / \mathrm{M} / \mathrm{nbr}$ & $\begin{array}{l}\text { Face, tronco e membros superiores; pápulas eritematosas com } 0,6 \mathrm{~cm} \\
\text { de diâmetro médio }\end{array}$ & $\begin{array}{l}\text { vasculítico com } \\
\text { leucocitoclasia }\end{array}$ \\
\hline 17 & $38 / F / b r$ & Língua; úlcera com $1 \mathrm{~cm}$ & granulomatoso \\
\hline 18 & $24 / \mathrm{M} / \mathrm{br}$ & Face; úlceras com $0,4 \mathrm{~cm}$ & macrofágico difuso \\
\hline 19 & $30 / \mathrm{F} / \mathrm{br}$ & Mucosa oral (palato); lesão do tipo estomatite moruliforme & macrofágico difuso \\
\hline 20 & $39 / \mathrm{F} / \mathrm{nbr}$ & $\begin{array}{l}\text { Face e membros superiores; pápulas eritematosas com } 1 \mathrm{~cm} \text { de diâmetro } \\
\text { médio }\end{array}$ & macrofágico difuso \\
\hline 21 & $25 / \mathrm{M} / \mathrm{br}$ & Face; pápulas eritematosas com depressão central & macrofágico difuso \\
\hline 22 & 28/M/br & Face, couro cabeludo e dorso; úlceras com 4 e $6 \mathrm{~mm}$ & macrofágico difuso \\
\hline 23 & $46 / \mathrm{M} / \mathrm{br}$ & Face; pápulas ulceradas com $0,5 \mathrm{~cm}$ & macrofágico difuso \\
\hline 24 & 29/M/br & Palato; úlcera & granulomatoso \\
\hline 25 & $25 / \mathrm{M} / \mathrm{br}$ & $\begin{array}{l}\text { Membros inferiores e região plantar; pápulas em membros inferiores } \\
\text { e úlcera com } 3 \mathrm{~cm}\end{array}$ & granulomatoso \\
\hline
\end{tabular}

$\mathrm{F}=$ feminino; $\mathrm{M}=$ masculino; $\mathrm{br}=$ branco; $\mathrm{nbr}=$ não brancos.

com leucocitoclasia: foi visto em cinco casos, teve como característica infiltrado inflamatório mono e polimorfonuclear com leucocitoclasia, em torno e na parede de capilares e vênulas, com deposição de fibrina no endotélio. Apresentava ainda moderada quantidade de células CD68, pequena quantidade de células UCHL-1 e escassas células L26. Moderada quantidade de células fúngicas foi observada em meio aos restos celulares (Figura 6); c) granulomatoso: foi observado em dois casos e caracterizou-se por processo inflamatório crônico, com acúmulos de células epitelióides e ocasionais células gigantes multinucleadas na derme, moderada quantidade de células CD68 e UCHL-1 e pequena quantidade de células L26. Pequena a moderada quantidade de células fúngicas foi observada no interior de macrófagos (Figura 7); d) escassa reação inflamatória: este tipo foi visto em dois casos. Caracterizou-se por apresentar na derme capilares dilatados e ciscunscritos por discreto infiltrado inflamatório mononuclear, com pequena quantidade de células CD68, escassas células UCHL-1 e L26. Observou-se ainda moderada quantidade de células do fungo, dispersas predominantemente fora das células, permeando livremente as fibras colágenas (Figura 8). As lesões da mucosa oral eram do tipo macrofágico difuso (5 casos) e granulomatoso (2 casos), localizavamse no corion superficial e profundo, e apresentavam as mesmas características histológicas e imunohistoquímicas daquelas da derme. 

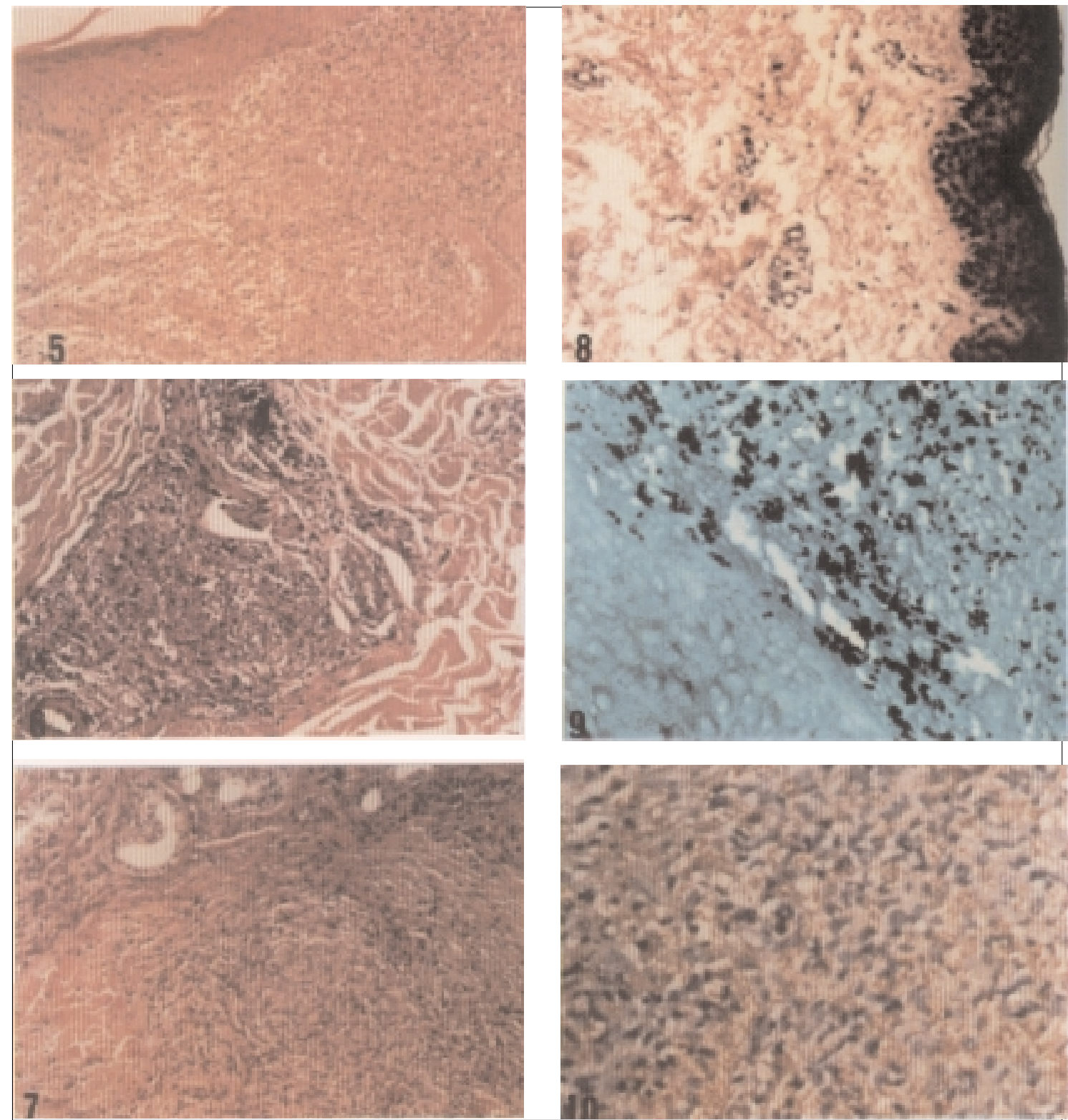

Figura 5 - Infiltrado inflamatório predominantemente macrofágico difuso permeando a derme. HE x 100.

Figura 6 - Infiltrado inflamatório predominantemente perivascular na derme. HE x 100.

Figura 7 - Infiltrado inflamatório predominantemente mononuclear permeado por acúmulos de células epitelióides e ocasionais células gigantes multinucleadas do tipo Langhans. HE x 100.

Figura 8 - Discreto infiltrado inflamatório mononuclear em torno de vasos da derme. HE x100.

Figura 9 - Histoplasma capsulatum em grande quantidade na derme. Grocott-prata-metanamina x 400.

Figura 10 - Histoplasma capsulatum. Reação do tipo estreptavidina-biotina (anticorpo policlonal anti-Histoplasma capsulatum) x 400 . 


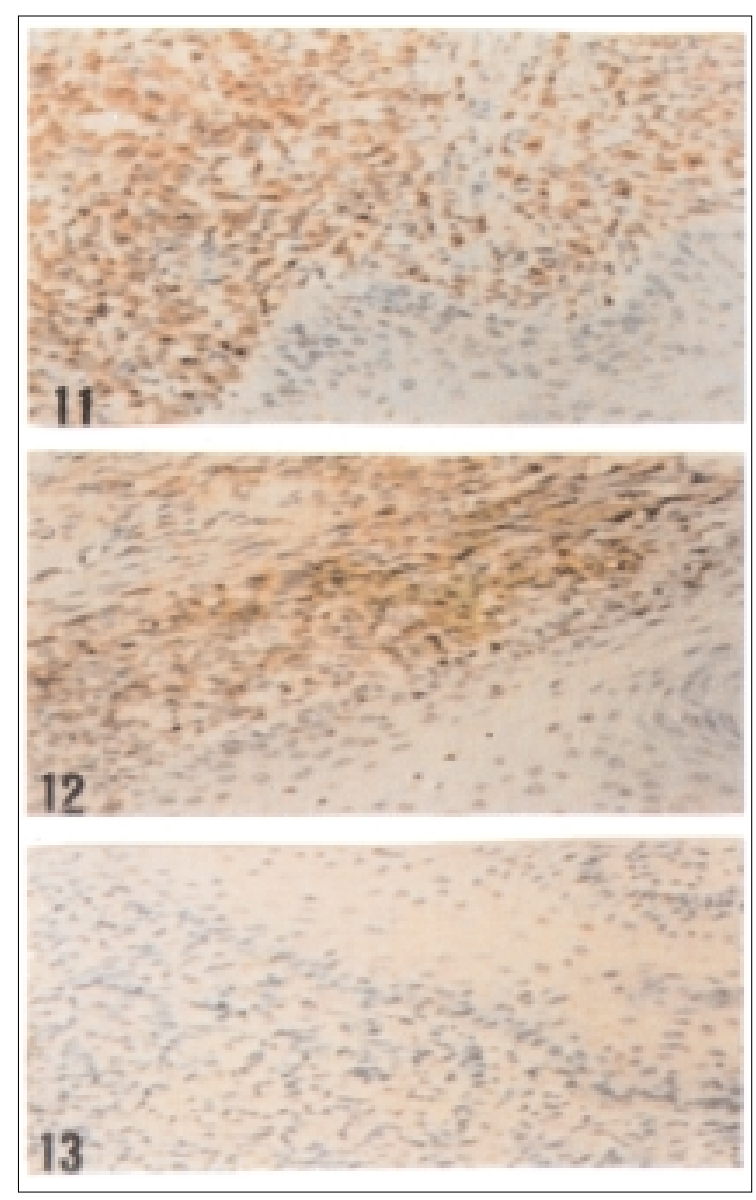

Figura 11 - Células CD68 em grande quantidade. Reação do tipo estreptavidina-biotina (anticorpo monoclonal antimacrófafo humano) x 100 .

Figura 12 - Células UCHL-1 em moderada quantidade. Reação do tipo estreptavidina-biotina (anticorpo monoclonal antilinfócitoT-) $\times 100$.

Figura 13 - Ausência de células L26. Reação tipo estreptavidina-biotina (anticorpo monoclonal antilinfócito
X) 100 .

\section{DISCUSSÃO}

O envolvimento cutâneo e da mucosa oral, na histoplasmose disseminada em aidéticos, é quase exclusivamente o resultado da disseminação hematogênica do $H$. capsulatum e, sua ocorrência segundo dados de literatura varia de 1,4 a 85\%26 1516171820 . No Brasil, não encontramos dados sobre a freqüência das manifestações cutânea e da mucosa oral na histoplasmose disseminada associada à AIDS. Nos EUA8 e na Argentina16, entretanto, referem que esta freqüência é de 10 a $25 \%$ e $87 \%$, respectivamente. Embora não tenhamos realizado estudo da freqüência dessa associação, ela nos parece ser elevada em nosso meio.

Nossas observações sobre a histoplasmose disseminada cutânea e da mucosa oral em pacientes aidéticos confirmam os dados da literatura1 36812141617 18, no que se refere ao caráter multiforme das lesões e sua localização predominantemente na face, tronco e membros superiores.

Do ponto de vista histopatológico nossos achados na pele confirmam também a existência de quatro padrões morfológicos na presença do $H$. capsulatum, a saber: macrofágico difuso10; vasculítico com leucocitoclasia7 8; granulomatoso 13 e com escassa reação inflamatória11 $1213 . \mathrm{Na}$ mucosa oral, observamos apenas os padrões macrofágico difuso e granulomatoso, com predomínio do primeiro. A razão desta diferença necessita melhor investigação. Por outro lado, não parece haver correlação entre os padrões histológicos e as lesões clínicas.

Entretanto, os diferentes padrões de resposta tecidual estão provavelmente relacionados com o perfil imunológico dos pacientes. De fato, a tipagem através de marcadores celulares para linfócitos T, B e macrófagos, realizada em 12 casos, mostrou, de modo geral, moderada ou grande quantidade de macrófagos, pequena ou moderada quantidade de linfócitos T e escassez de linfócitos $B$ nos diferentes tipos de reação tecidual.

O padrão macrofágico difuso, segundo Goodwing et al10, é o mais característico da forma disseminada. A alteração numérica e funcional dos linfócitos CD4+ parece resultar em menor diferenciação dessas células no subtipo Th1 e, conseqüentemente, na deficiência da produção de interleucinas necessárias à ativação dos macrófagos que se tornam incapazes de destruir o fungo e de deter sua multiplicação5 21. De fato, como foi visto em nosso material, tanto na pele como na mucosa oral, existe um infiltrado inflamatório difuso, composto predominantemente por células CD68 repletas de células fúngicas, associadas a escassas células L26 e a pequena quantidade de células UCHL-1.

O padrão vasculítico com leucocitoclasia descrito por Cohen et al7 e Eidbo et al8 e, por este último autor interpretado como indicando uma marcada imunodepressão, ao nosso modo de ver, parece representar uma vasculite por deposição de imunocomplexo na parede dos vasos (reação de hipersensibilidade). A reação imunohistoquímica mostrou escassas células 
L26, pequena quantidade de células UCHL-1 e moderada de células CD68. Paralelamente observamos moderada quantidade de fungos.

Quanto ao padrão granulomatoso, nossos achados coincidem com os de Goodwing et al10 e Hoffman et al13, embora este padrão represente um menor grau de comprometimento da imunidade celular, principalmente da resposta TH1. Conforme foi visto nas lesões cutâneas, há maior quantidade de células L26 e de células UCHL-1 e menor quantidade de células CD68 em relação ao tipo macrofágico difuso; paralelamente há quantidade menor de células fúngicas.

O padrão com escassa reação inflamatória, descrito por Hernandez et al12, Greenberg e Berger11 e Hofman et al13 talvez represente um acentuado grau de comprometimento da imunidade celular, envolvendo tanto a resposta Th1 como Th2. Conforme observamos através do estudo imunohistoquímico, há escassas células L26 e UCHL-1 e pequena quantidade de células CD68; paralelamente, há moderada quantidade de células fúngicas crescendo livremente em torno de vasos e permeando fibras colágenas. Contudo para melhor sustentação daquela hipótese seria necessário realização de protocolo para estudo da quantidade de linfócitos T CD4 no sangue periférico.

Embora tenhamos realizado reação imunohistoquímica tipo estreptavidina-biotina (anticorpo policlonal anti-histoplasma) para caracterização do $H$. capsulatum em apenas doze casos, mas incluindo todos os tipos histológicos, acreditamos que o resultado dessa amostra possa ser extrapolado para os demais casos. Esse tipo de exame é útil devido à sua alta especificidade e rapidez com que pode fornecer o diagnóstico etiológico, substituindo a cultura que demora duas a três semanas para ser obtido; os pacientes aidéticos necessitam de diagnóstico precoce e tratamento imediato.

\section{REFERÊNCIAS BIBLIOGRÁFICAS}

1. Antônio JR, Gon AS, Franco C, Maia LI, Salles VMR, Pozetti EMO. Histoplasmose cutânea na síndrome da imunodeficiência adquirida. Anais Brasileiros de Dermatologia 67:223-226, 1992.

2. Arévalo C, Seivane D, Rodrigues $H$, Calebotta A. Histoplasmosis en pacientes con SIDA: presentación de dos casos con lesiones en la lengua y en piel respectivamente. Dermatologia Venezolana 28:2529, 1990.

3. Carme B, Itoua-Ngaporo A, Bourgarel J, Poste B. Histoplamose a Histoplasma capsulatum. Bulletin de la Societé de Pathologie Exotique 77:653-657, 1984.

4. Center for Disease Control. Revision of the case definition of aquired immune deficiency syndrome for national reporting. United States. Morbidity and Mortality Weekly Report 34:373-375, 1985.

5. Chaturvedi S, Frame P, Newman LS. Macrophages from human immunodeficiency virus-positive persons are defective in host defense against Histoplasma capsulatum. Journal of Infectious Diseases 171:320327, 1995.

6. Cirillo-Hyland VA, Gross P. Disseminated histoplasmosis in a patient with acquired immunodeficiency syndrome. Cutis 55:161-164, 1995.

7. Cohen PR, Bank DE, Grossman ME, Silvers DN. Cutaneous lesions of disseminated histoplasmosis in human immunodeficiency virus infection patients. Journal of the American Academy of Dermatology 23:422-428, 1990.
8. Eidbo J, Sanchez RL, Tschen JA, Ellner KM. Cutaneous manifestations of histoplasmosis in the acquired immune deficiency syndrome. The American Journal of Surgical Pathology 17:110-118, 1993.

9. Garcia NM, Assis CM, Del Negro GMB, Lacaz CS. Obtenção de exoantígeno de Histoplasma capsulatum em meio de neopeptona, glicose, tiamina, aspargina (NGTA). Revista do Instituto de Medicina Tropical de São Paulo 32:370-374, 1990.

10. Goodwing Jr RA, Shapiro JL, Thurman GH, Thurman SS, Des Prez RM. Disseminated histoplasmosis: clinical and pathologic correlations. Medicina 59:133, 1980.

11. Greenberg RG, Berger TG. Progressive disseminated histoplasmosis in acquired immune deficiency syndrome: presentation as a steroid-resposive dermatosis. Cutis 43:535-538, 1989.

12. Hernandez DE, Morgenstern J, Weiss E, Planas G, Ruiz A, Olavarria R, Tapia F, Muci R, Vargas R, Wuani H. Cutaneous lesions of disseminated histoplasmosis in a haitian man with the acquired immunodeficiency syndrome. International Journal of Dermatology 25:117-118, 1986.

13. Hofman P, Michiel SJF, Saint-Paul MC, Loubière R. Aspects histologiques des infections mycotiques au coors du syndrome d'immunideficence acquise (SIDA). Archives D Anatomie et de Cytologie Pathologiques 41:193-204, 1993.

14. Ibanez HE, Ibanez MA. Case report: A new presentation of disseminates histoplasmosis in a 
homossexual man with AIDS. American Journal of Medical Sciences 298:407-409, 1989.

15. Johnson PC, Khadori N, Najjar AF, Butt $F$, Manssel PWA, Sarosi GA. Progressive disseminated histoplamosis in patients with acquired immunodeficiency syndrome. The American Journal of Medicine 85:152-158, 1988.

16. Negroni R. Micosis en pacientes con SIDA. Revista Argentina de Micología 13:3-14, 1990.

17. Petit N, Bonnet E, Chapel F, Bensa P, Gallais $H$, Lebreuil G. Cutaneous biopsies for diagnosis of histoplasmosis in na HIV patient. Infection 22:426427, 1994.

18. Wasserteil V, Acosta FJJ, Kerdel FA. Disseminated histoplasmosis presenting as a rosacea- like eruption in a patient with the acquired immunodeficiency syndrome. International Journal of Dermatology 29:649-651, 1990.

19. Wheat LS, Slama TG, Zeckel ML. Histoplasmosis in the acquired immune deficiency syndrome. American Journal of Medicine 78:203-210, 1984.

20. Wheat LS, Strigfield PAC, Baker RL, Curfman MF, Eads ME, Israel SK, Norris SA, Webb DH, Zeckel ML. Disseminated histoplasmosis in the acquired immune deficiency syndrome: clinical findings, diagnosis and treatment, and review of literature. Medicine 69:361-374, 1990.

21. Zhou P, Sieve MC, Bennett J, Knon-Chung J, Tewari RP, Sher A, Seder RA. IL-12 prevents mortality in mice infected with Histoplasma capsulatum througt induction of TFN- gama. Journal of Immunology 155:785-795, 1995 